\title{
Modified Nucleosides - Molecular Markers Suitable for Small-volume Cancer?
}

\author{
PHILIPP OPITZ ${ }^{1}$, OLF HERBARTH ${ }^{2,3}$, ANNEROSE SEIDEL ${ }^{2}$, ANDREAS BOEHM ${ }^{4}$, \\ MILOS FISCHER ${ }^{4}$, CHRISTIAN MOZET ${ }^{4}$, ANDREAS DIETZ ${ }^{3,4}$ and GUNNAR WICHMANN ${ }^{3,4}$ \\ ${ }^{1}$ Institute of Hygiene, Hospital Hygiene and Environmental Medicine, \\ University Hospital Leipzig, Leipzig, Germany; \\ ${ }^{2}$ Institute of Environmental Medicine and Hygiene, Faculty of Medicine, University of Leipzig, Leipzig, Germany; \\ ${ }^{3}$ LIFE-Leipzig Research Center for Civilization Diseases, University of Leipzig, Leipzig, Germany; \\ ${ }^{4}$ Clinic for Otorhinolaryngology, Head and Neck Surgery, University Hospital Leipzig, Leipzig, Germany
}

\begin{abstract}
Background: Modified nucleosides (mNS) in urine are shown to be encouraging markers in cancer, mostly in patients presenting with high tumor mass such is breast and lung cancer. To our knowledge, $m N S$ have not been investigated in head and neck squamous cell carcinoma (HNSCC). HNSCC is characterized by early metastasis into locoregional lymph nodes and slow infiltrating growth, but even in the advanced stage exhibits only a relatively low cancer volume. Therefore, reliable distinction between HNSCC and healthy controls by urinary $\mathrm{mNS}$ might pose substantial analytical problems and even more as patients with HNSCC mostly have an increased exposure to tobacco smoke and excessive alcohol consumption which affect the renal mNS pattern. Materials and Methods: Urinary $m N S$ in samples of 93 therapy-naive patients with HNSCC and 242 healthy controls were quantified by reversedphase high-performance liquid chromatography. Considering that the circadian rhythm causes diuresis-induced variations in concentration, the mNS-to-creatinine ratio was chosen to compare patients and controls. For sensitivity and specificity in discriminating between patients and controls, the corresponding curve was plotted. Additionally, logistic regression was carried out and a multilayer perceptron neuronal network (NN) was created. Results: Fifteen mNS were detectable in cases and controls; concentrations of 11 were found to be significantly different. The sensitivity and specificity depend on the total
\end{abstract}

Correspondence to: Philipp Opitz, Ph.D., Institute of Hygiene, Hospital Hygiene and Environmental Medicine, University Hospital Leipzig, Johannisallee 34, 04103 Leipzig, Germany. Tel: +49 3419715304, Fax: +49 3419715309, e-mail: Philipp.Opitz@medizin.uni-leipzig.de

Key Words: Tumor marker, modified nucleosides, RNA turnover, non-invasive diagnostics, head and neck squamous cell carcinoma, HNSCC, reversed-phase high-performance liquid chromatographic, RP-HPLC. volume of the lesion; HNSCC with volume $<20 \mathrm{ml}$ was reliably detected, but those with a volume of $20 \mathrm{ml}$ or greater produced amounts of mNS which led to the most accurate detection of HNSCC based on HNSCC-specific mNS patterns. Conclusion: Analysis of urinary $\mathrm{mNS}$ allows for detection of small-volume HNSCC, with acceptable specificity and sensitivity if the tumor volume exceeds $20 \mathrm{ml}$.

The turnover of ribonucleic acid (RNA) seems to be a suitable indicator in patients with malignant neoplasia, especially for those with tumors with a large volume such as breast cancer, lung cancer and others (1-4). Modified nucleosides (mNS) are generated from a number of RNA species post transcriptionally during pre-RNA maturation through enzymatically catalyzed processes such as methylation, hydroxylation, deamination, and saturation of double bonds $(5,6)$. To date about $90 \mathrm{mNS}$ are known. Free mNS result from the metabolism of RNA after the completion of protein biosynthesis as these mNS cannot be reused by the salvage pathway for synthesis of new RNA molecules $(4,7)$. Hence, because of expedited RNA metabolism in tumors compared to healthy tissue, mNS will be excreted quantitatively via urine in increased amounts $(7,8)$.

The main goal of this study was to answer the question of whether the altered spectrum of excreted $\mathrm{mNS}$ differs in cancer entities with bulky tumors and whether it is possible to detect rather slow-growing low-volume cancer such as head and neck squamous cell carcinomas (HNSCC). In other words, do small cancer volumes produce sufficient amounts of mNS in the urine samples of patients which can be detected using reversedphase high-performance liquid chromatography (RP-HPLC).

\section{Materials and Methods}

Starting point. Starting from the results of our already published studies from 2006, 2007 and 2014 (9-11), the spectrum of mNS measured in urine was supplemented by hypoxanthosine, L-tryptophan 
Table I. Short names, systematic nomenclature, limit of detection, retention time, standard deviation and calibration curve R2 for the investigated nucleosides.

\begin{tabular}{|c|c|c|c|c|c|c|}
\hline Nucleoside & $\begin{array}{l}\text { Short } \\
\text { name }\end{array}$ & $\begin{array}{c}\text { New } \\
\text { nomenclature }\end{array}$ & $\begin{array}{l}\text { Limit of detection } \\
(\mathrm{nmol} / \mathrm{ml})\end{array}$ & $\begin{array}{l}\text { Retention time } \\
\quad(\min )\end{array}$ & $\begin{array}{c}\text { Coefficient of } \\
\text { variation }(\%)\end{array}$ & $\begin{array}{c}\text { Calibration } \\
\mathrm{R}^{2}\end{array}$ \\
\hline Pseudouridine & Psi (Y) & $9 \mathrm{U}$ & 0.128 & 5.2 & 0.43 & 0.9998 \\
\hline Cytidine & $\mathrm{C}$ & $\mathrm{C}$ & 0.140 & 6.6 & 0.48 & 0.9998 \\
\hline Hypoxanthosine & HXan & - & 0.056 & 7.6 & 1.26 & 0.9989 \\
\hline 3-Methylcytidine & $\mathrm{m} 3 \mathrm{C}$ & $3 \mathrm{C}$ & 0.190 & 8.8 & 1.92 & 0.9975 \\
\hline Uridine & $\mathrm{U}$ & $\mathrm{U}$ & 0.134 & 9.3 & 0.54 & 0.9998 \\
\hline 1-Methyladenosine & $\mathrm{m} 1 \mathrm{~A}$ & $1 \mathrm{~A}$ & 0.119 & 10.3 & 1.97 & 0.9975 \\
\hline 5-Methylcytidine & $\mathrm{m} 5 \mathrm{C}$ & $5 \mathrm{C}$ & 0.122 & 12.5 & 3.09 & 0.9936 \\
\hline Guanosine & G & $\mathrm{G}$ & 0.114 & 19.2 & 2.82 & 0.9943 \\
\hline Xanthosine & Xan & - & 0.060 & 20.0 & 0.62 & 0.9997 \\
\hline 1-Methylinosine & $\mathrm{m} 1 \mathrm{I}$ & $19 \mathrm{~A}$ & 0.122 & 22.8 & 7.11 & 0.9703 \\
\hline 1-Methylguanosine & $\mathrm{m} 1 \mathrm{G}$ & $1 \mathrm{G}$ & 0.113 & 23.4 & 2.28 & 0.9966 \\
\hline L-Tryptophan & L-Tryp & - & 0,121 & 24.1 & 1.88 & 0.9977 \\
\hline 2-Methylguanosine & $\mathrm{m} 2 \mathrm{G}$ & $2 \mathrm{G}$ & 0.133 & 24.2 & 1.63 & 0.9983 \\
\hline$N 2, N 2$-Dimethylguanosine & $\mathrm{m} 2,2 \mathrm{G}$ & $22 \mathrm{G}$ & 0.022 & 27.4 & 1.35 & 0.9987 \\
\hline N6-Methyladenosine & m6A & $6 \mathrm{~A}$ & 0.189 & 32.9 & 1.03 & 0.9993 \\
\hline
\end{tabular}

$\mathrm{R}^{2}$ (determination coefficient): An estimate of how well the five-point calibration fit in a straight line.

and guanosine (Table I). In total, $15 \mathrm{mNS}$ and the sum of all measured mNS were quantified in the urine of study participants.

Reagents. The following mNS standards were purchased from Sigma (St Louis, MO, USA): pseudouridine, uridine, cytidine, 1-methyladenosine, 5-methylcytidine, 1-methylinosine, guanosine, xanthosine, 1-methylguanosine, 2-methylguanosine, N2,N2dimethylguanosine, N6-methyladenosine, hypoxanthosine and Ltryptophan. All of them were of HPLC purity. Ammonium dihydrogen phosphate buffer $\left(\mathrm{NH}_{4} \mathrm{H}_{2} \mathrm{PO}_{4}\right)$, methanol and acetonitrile were obtained from Baker (Phillipsburg, NJ, USA) of Baker-analyzed HPLC grade. Deionized water was acquired from a Milli O plus purification system (Millipore, Bedford, MA, USA).

Patients and study population, and collection of urine samples. Between 08/2009 and 05/2012, patients suspected as having HNSCC underwent tumor consultation in the head and neck (Ear, Nose and Throat) clinic of the University Hospital Leipzig. In total 93 patients with pathohistological confirmed HNSCC were included in the study (Table II). The localization of the primary tumors comprised the larynx, hypopharynx, oropharynx, and oral cavity. In all cases, the urine sample was taken before starting therapy with curative intent.

Healthy controls $(n=242)$ were matched approximately $3: 1$ with HNSCC cases. Matching criteria were age, sex and the predominant lifestyle factors in patients with HNSCC, i.e. tobacco smoking and alcohol consumption. It should be noted that matching regarding lifestyle factors was not possible in detail for each case. The controls were recruited from different studies: LIFE (Leipzig Research Center for Civilization Diseases), ENT Clinic (patients without cancer, inflammatory diseases or pregnancy), and an internal study for creation of reference values.

All urine samples were taken after obtaining written patient's informed consent as approved by the local Institutional Review Board (Ethics Committee of the Medical Faculty of the University Leipzig: NUCLEO No. 201-10-12072010 and No. 202-10-12072010).
All urine samples were filtered immediately using a $0.2 \mu \mathrm{m}$ membrane cellulose acetate filter (Sartorius, Göttingen, Lower Saxony, Germany) to remove any sediment potentially containing epithelial cells, erythrocytes, bacteria and proteins which might interfere with further analysis. The filtered urine samples were stored at $-20^{\circ} \mathrm{C}$ no longer than 8 weeks until processed. This storage conditions do not lead to any changes in the nucleoside concentration as shown earlier (9). According to the study design and availability only of spontaneous urine, the urine samples were normalized according to their creatinine content.

Sample preparation. Solid-phase extraction (SPE) of urinary mNS was carried out on Oasis HLB extraction cartridges (Baker, Deventer, Overijssel, Netherland) which possessing specific affinity for cishydroxyl groups. SPE was performed to eliminate DNA and amino acids present in the urine samples. The columns were preconditioned with $1.0 \mathrm{ml}$ acetonitrile, followed by $3.0 \mathrm{ml}$ methanol and $3.0 \mathrm{ml}$ distilled water. The recovery of $\mathrm{mNS}$ was

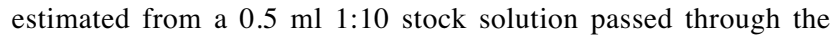
columns. All analyses of the urine were based on a volume of 0.5 $\mathrm{ml}$. The columns were eluted with $1.0 \mathrm{ml}$ methanol, $1.0 \mathrm{ml}$ acetonitrile and $1.0 \mathrm{ml}$ methanol. The samples were then evaporated to dryness at $40^{\circ} \mathrm{C}$ and dissolved in $0.5 \mathrm{ml} 0.01 \mathrm{~mol} / 1 \mathrm{NH}_{4} \mathrm{H}_{2} \mathrm{PO}_{4}$ buffer. A sample volume of $20 \mu \mathrm{l}$ was injected into the RP-HPLC system and analyzed.

Determination of $m N S$. The chromatographic conditions used for the HPLC separation of mNS were based on the method developed by Gehrke and Kuo et al. (12). HPLC separation was accomplished using an Ultimate 3000 from Thermo Fisher Scientific (Thermo Fisher Scientific, Waltham, MA, USA) equipped with an auto sampler WPS 3000 and DAD detector 3000 for quantification at a wavelength of $254 \mathrm{~nm}$. Separation of the mNS was achieved using a $(250 \times 4.6 \mathrm{~mm}$ ID) LC-18-S Supelcosil column protected with a guard cartridge $(2.1 \times 4.6 \mathrm{~mm}$ ID) LC-18-S Supelcosil (Sigma- 
Aldrich, Bellefonte, PA, USA). For quantification of the mNS and creatinine, a four-point calibration curve was produced. mNS were identified by matching their retention times and absorption spectra to the analytical references. Data acquisition and processing of the chromatograms were conducted with Chromeleon software version 6.8 (Thermo Fisher Scientific).

The reproducibility of the method including the extraction was determined in six repetitive analyses using the same spontaneous urine sample from a healthy person, additionally, the determination of the correlation coefficient $\left(\mathrm{R}^{2}\right)$ of a five-point calibration was added (Table I). Moreover, recovery rates for all mNS were determined by spiking 10 different urine samples of controls prior to their extraction. Each urine sample was measured in triplicate; for all mNS, the recovery rate was between $89 \%$ and $104 \%$. As a $24-\mathrm{h}$ urine sample of participants was not available, the mNS-to-creatinine ratio was chosen to compare patients with controls and to consider the diuresis-induced variations in concentration due to the circadian rhythm. A substantial advance of the applied method is the simultaneous determination of $\mathrm{mNS}$ and creatinine of urine samples as described in our previous studies (9-11).

Estimation of tumor burden for assessment of volume-dependent $m N S$ excretion. Compared with breast cancer and cancer of stomach or lung, which are characterized by high tumor volumes, head and neck cancer can be characterized as a small-volume cancer. Because it can be assumed that the volume of cancer reflects the number of cancer cells, the tumor volume should influence the production of mNS and the amount excreted and appearing in urine. Since the TNM categories (13) of the patients with HNSCC were available and some of the HNSCC in an accompanying study underwent volume assessment via computed tomography-based volumetry via image segmentation (14), the total volume of the malignant lesions was calculated after estimation of the volumes of the primary $\operatorname{HNSCC}(\mathrm{T})$ and potentially present locoregional lymph node metastases $(\mathrm{N})$ and distant metastases (M).

Statistic analysis. The Kolmogorow-Smirnow test was used to examine the distribution of the data set; f the Student's $t$-test was used to determine the significant differences between groups. The cut off-values were generated by the following equation: mean+ $\left(t_{\alpha=0.05}=1.96\right) \times($ standard error of the mean; SEM $)$ of the healthy population. For determining the sensitivity and specificity, the respective receiver operating characteristics (ROC) curve was plotted. By means of a logistic regression model, the influence and magnitude of the independent variables on the dichotomous target variable (healthy controls/patients with HNSCC) were verified. Furthermore, for the separation between controls and cases, a multilayer perceptron neuronal network $(\mathrm{NN})$ was created with SPSS 20 (IBM Corporation, Armonk, NY, USA). The neural network analysis was carried out considering the following conditions: $70 \%$ training, $15 \%$ test and $15 \%$ validation dataset. The best model was in every case a network type of multilayer perceptron with an error function of "cross entropy", activation function "tanh" and output units "softmax".

Statistical analyses were carried out using Microsoft Office Excel $^{\circledR} 2010$ (Microsoft Deutschland GmbH, Unterschleißheim, Germany), SPSS 20 (IBM Corporation, Armonk, NY, USA), and STATISTICA 10 (StatSoft Inc., Tulsa, OK, USA).
Table II. Clinical characteristics of the head and neck squamous cell carcinoma group

\begin{tabular}{lc}
\hline Characteristic & Value \\
\hline Age, years & \\
Mean (range) & $60.4(40.1-81.8)$ \\
Gender, n (\%) & \\
Male & $79(84.9 \%)$ \\
Female & $14(15.1 \%)$ \\
UICC stage, n (\%) & \\
I & $10(10.8 \%)$ \\
II & $9(9.7 \%)$ \\
III & $15(16.1 \%)$ \\
IVA & $50(53.8 \%)$ \\
IVB & $6(6.5 \%)$ \\
IVC & $3(3.2 \%)$ \\
Tumor location, n $(\%)$ & \\
Oropharynx & $40(43.0 \%)$ \\
Hypopharynx & $18(19.4 \%)$ \\
Larynx & $29(31.2 \%)$ \\
Oral cavity & $6(6.5 \%)$ \\
Tobacco consumption, n (\%) & $75(81.5 \%)$ \\
Yes & $17(18.5 \%)$ \\
No & $78(84.8 \%)$ \\
Alcohol consumption, n $(\%)$ & $14(15.2 \%)$ \\
Yes & \\
No & \\
\hline
\end{tabular}

UICC: International Union for Cancer Control staging system (24).

\section{Results}

The entire study population was characterized by a mean age of 58 years (cases $=60$ years; controls $=57$ years) and a ratio between males and females of $85: 15$. Table II gives an overview of the main characteristics of the investigated study population.

Altogether, $20 \mathrm{mNS}$ and creatinine in urine were determined; 15 of these were excreted at elevated level in patients with tumor, whereas for five mNS there was an inverse relationship for concentrations between controls and cases. These $15 \mathrm{mNS}$ were included in further statistical analysis, whereby six out of these 15 were detectable only around the limit of quantification.

As initial results demonstrated not only increased concentrations of $\mathrm{mNS}$, but also slightly increased creatinine concentrations in urine of patients with HNSCC, mNS concentrations were normalized to creatinine content (Table III) and compared but this did not lead to substantial changes with respect to the observed differences. Table III constitutes the results of the significant and non-significant differences comparing cases and controls using Student's $t$-test.

The proportions of $\mathrm{mNS}$ (above $4 \%$ ) relative to the sum of all nucleosides and classified for both groups (healthy controls, HNSCC) are illustrated in Figure 1. Whereas the 
Table III. Creatinine-normalized concentrations (nmol/umol creatinine) in urine of the 15 modified nucleosides detected by reversed-phase highperformance liquid chromatography.

\begin{tabular}{|c|c|c|c|c|c|c|c|c|c|c|}
\hline \multirow[b]{2}{*}{ Short name* } & \multicolumn{5}{|c|}{ While cohort $(n=335)$} & \multicolumn{2}{|c|}{$\operatorname{HNSCC}(\mathrm{n}=93)$} & \multicolumn{2}{|c|}{ Controls $(\mathrm{n}=242)$} & \multirow[b]{2}{*}{$p$-Value ${ }^{\mathrm{a}}$} \\
\hline & Mean & Median & Min & $\operatorname{Max}$ & SE & Mean & SE & Mean & SE & \\
\hline Psi & 42.090 & 40.701 & 0.070 & 102.175 & 0.707 & 46.050 & 1.533 & 40.569 & 0.762 & $<0.001$ \\
\hline $\mathrm{C}$ & 0.828 & 0.065 & 0.013 & 18.859 & 0.137 & 1.340 & 0.355 & 0.631 & 0.130 & 0.020 \\
\hline HXan & 13.372 & 7.308 & 0.012 & 384.350 & 1.914 & 20.886 & 5.231 & 10.484 & 1.699 & 0.015 \\
\hline $\mathrm{U}$ & 7.604 & 4.132 & 0.018 & 183.356 & 0.831 & 9.826 & 1.579 & 6.750 & 0.973 & 0.097 \\
\hline $\mathrm{m} 3 \mathrm{C}$ & 1.758 & 0.085 & 0.018 & 58.246 & 0.365 & 3.883 & 1.093 & 0.941 & 0.265 & $<0.001$ \\
\hline $\mathrm{m} 1 \mathrm{~A}$ & 6.311 & 2.561 & 0.026 & 125.574 & 0.745 & 8.487 & 1.769 & 5.475 & 0.772 & 0.070 \\
\hline $\mathrm{m} 5 \mathrm{C}$ & 0.583 & 0.052 & 0.010 & 56.668 & 0.224 & 1.322 & 0.689 & 0.299 & 0.160 & 0.041 \\
\hline G & 2.472 & 0.829 & 0.010 & 137.519 & 0.528 & 4.507 & 1.579 & 1.689 & 0.401 & 0.017 \\
\hline Xan & 0.139 & 0.026 & 0.005 & 8.549 & 0.039 & 0.355 & 0.134 & 0.056 & 0.011 & $<0.001$ \\
\hline $\mathrm{m} 1 \mathrm{I}$ & 1.885 & 1.518 & 0.021 & 17.185 & 0.088 & 2.262 & 0.243 & 1.740 & 0.077 & 0.008 \\
\hline L-Tryp & 7.771 & 6.872 & 0.022 & 43.334 & 0.279 & 9.049 & 0.477 & 7.280 & 0.335 & 0.004 \\
\hline $\mathrm{m} 1 \mathrm{G}$ & 0.109 & 0.047 & 0.009 & 7.869 & 0.025 & 0.161 & 0.086 & 0.089 & 0.012 & 0.208 \\
\hline $\mathrm{m} 2 \mathrm{G}$ & 0.231 & 0.056 & 0.011 & 11.235 & 0.043 & 0.394 & 0.147 & 0.168 & 0.019 & 0.020 \\
\hline $\mathrm{m} 2,2 \mathrm{G}$ & 1.639 & 1.236 & 0.002 & 94.210 & 0.308 & 2.516 & 1.003 & 1.302 & 0.181 & 0.077 \\
\hline m6A & 31.131 & 0.381 & 0.015 & 1930.772 & 8.495 & 97.217 & 28.914 & 5.734 & 2.484 & $<0.001$ \\
\hline Sum & 117.921 & 74.248 & 33.435 & 2055.118 & 9.319 & 208.253 & 30.313 & 83.207 & 3.716 & $<0.001$ \\
\hline
\end{tabular}

SE: Standard error of the mean. *Please refer to Table I. aStudent's $t$-test.

nucleoside pseudouridine dominated in the healthy group at a proportion almost half of the sum of all excreted mNS, the spectrum shifted distinctly towards N6-methyladenosine among patients with HNSCC.

Eleven out of the 15 analyzed mNS were significantly increased in the case group, namely pseudouridine, cytidine, hypoxanthosine, 3-methylcytidine, 5-methylcytidine, guanosine, xanthosine, 1-methylinosine, L-tryptophan, 2-methylguanosine and N6-methyladenosine. Moreover, the sum of all excreted nucleosides was significantly increased in the patient group. For the comparison between controls and cases, values for the control group were used to define reference cut-off values.

The mNS with the most significant differences with respect to the $p$-values (pseudouridine, hypoxanthosine, 3-methylcytidine, guanosine, xanthosine, 1-methylinosine, L-tryptophan, N6-methyladenosine and the sum of all nucleosides) were selected to distinguish between healthy persons and patients with cancer. Depending on the number of mNS which exceeded the cut-off per study participant, the sensitivity and specificity were calculated for the whole cancer cohort (Table IV). This approach was carried out in accordance with the procedure described in Seidel et al. (9).

As already mentioned, head and neck cancer represents a cancer type with tumors of comparatively small volume. The volume of tumor therefore probably influences $\mathrm{mNS}$ excretion in urine. Since $20 \mathrm{ml}$ represented the median total volume estimated using the whole patient group, patients were dichotomized into groups with low $(<20 \mathrm{ml})$ and high ( $\geq 20 \mathrm{ml}$ ) cancer burden according to their tumor volume.
Table $\mathrm{V}$ shows the specificity and sensitivity for $\mathrm{mNS}$ in detection of head and neck cancer in patients with tumor volumes of $20 \mathrm{ml}$ or greater. As can be seen, the sensitivity increased for the same specificity by around $8.5 \%$ in the case of four mNS exceeding the cut-off nucleosides. The corresponding ROC curves demonstrate this fact (Figure 2).

During the further analysis, the dataset underwent logistic regression modeling $(n=247)$. On the basis of the adjusted odds ratios (OR) with $95 \%$ confidence interval (CI), the major risk factors alcohol $(\mathrm{OR}=2.0,95 \% \mathrm{CI}=1.2-3.2$; $p=0.001)$ and tobacco consumption $(\mathrm{OR}=2.7,95 \% \mathrm{CI}=1.3$ $5.8 ; p=0.013$ ) for HNSCC demonstrated a significant impact.

In a further step, a neural network was derived in an attempt to improve the accuracy of the prediction measured by sensitivity and specificity. Figure 3 shows the results obtained by applying neural networks for all cases and for cases with cancer volumes of $20 \mathrm{ml}$ and greater compared with the selection based on the cut-off values. The entire dataset was randomly split into $70 \%$ training, $15 \%$ test and $15 \%$ validation set. For the cut-off model, the sensitivity was $32 \%$ when used alone, and $41 \%$ when combined with tumor volume of $20 \mathrm{ml}$ or more based on $94 \%$ specificity. In comparison, the sensitivity increased to $35 \%$ for all cases and to $58 \%$ for tumor volume of $\geq 20 \mathrm{ml}$ for the neuronal network model.

\section{Discussion}

Based on studies in the past, the determination of $\mathrm{mNS}$ seems a suitable way to recognize patients with cancer $(15$, 


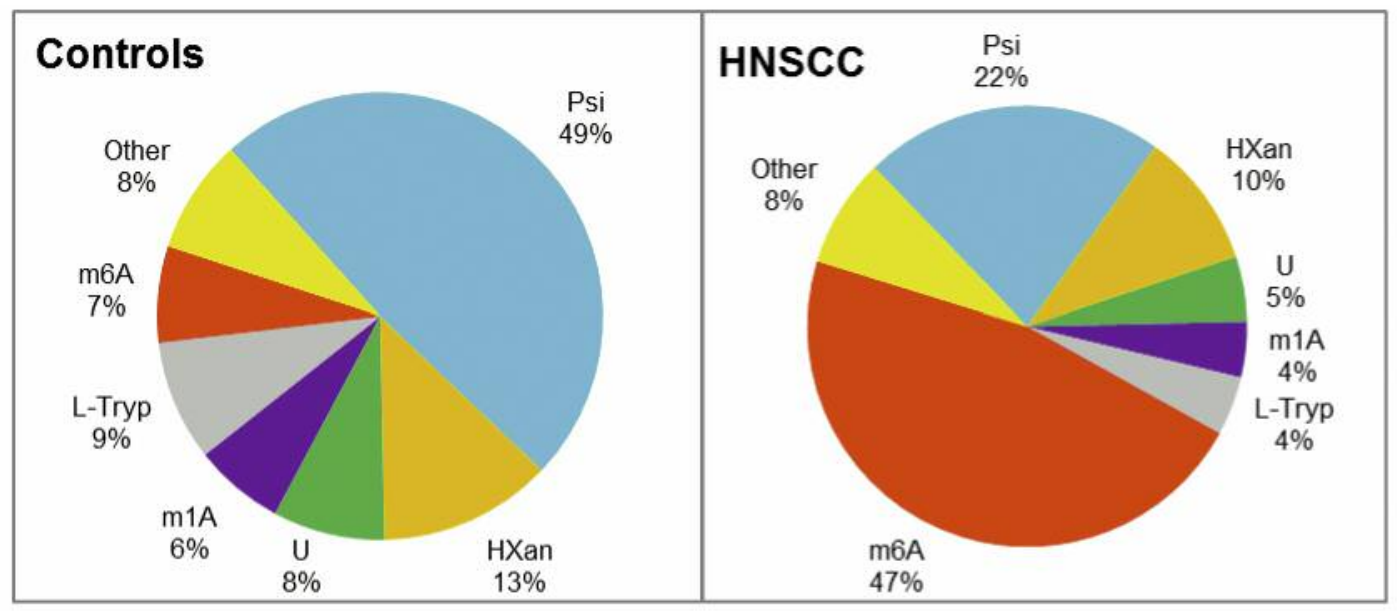

Figure 1. The proportions of modified nucleosides (>4\%) relative to the sum concentration of all nucleosides. Refer to Table I for full names.

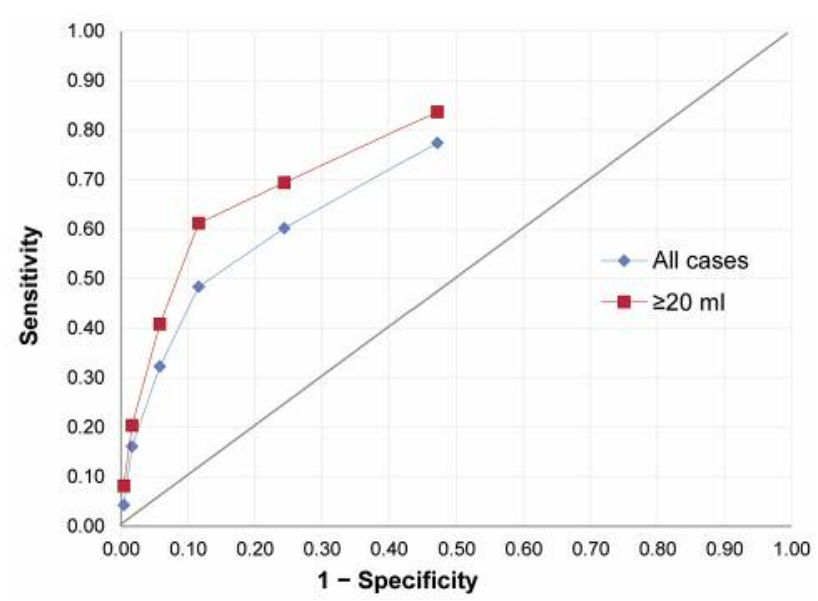

Figure 2. Receiver operation characteristic curve for sensitivity and specificity of the cut-off model according to tumor volume.

16). Compared with other studies, which also used patients with head and neck tumors for the case group, the six mNS we identified as markers do not concur. While there are relatively many studies on breast and colon cancer, the number of publications which investigated renal excretion of mNS with respect to HNSCC is limited. Roszkowski et al. identified significantly increased concentrations of 8oxoguanine and 8-oxodeoxyguanosine in blood and urine of patients with HNSCC (17). However, these two biomarkers result primarily from oxidatively damaged DNA and not from tRNA degradation. On the other hand, Dudley et al. demonstrated increased concentrations of 5-deoxycytidine in patients with stage IV head and neck tumors (18). In addition

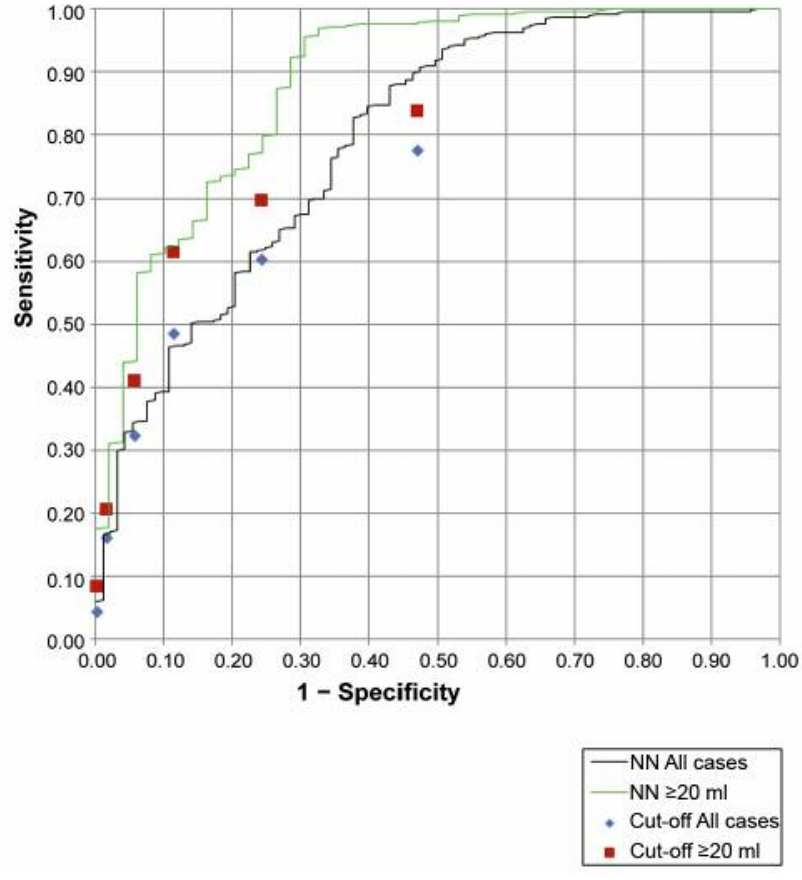

Figure 3. Receiver operation characteristic curve of sensitivity and specificity according to the estimated volume of the tumor and model of calculation. NN: Neural network.

to these two studies, that of Bullinger et al. was dedicated to the detection of hyper-modified nucleosides, but as well as HNSCC, the investigated case group involved a pool of cancer entities with bronchial and rectal carcinomas (19).

However, it should be noted out that the spectrum of significantly elevated mNS apparently depends on the particular 
Table IV. Sensitivity, specificity and Youden index of all patients for cutoff model using the number of modified nucleosides found at elevated concentration.

\begin{tabular}{lllllll}
\hline & \multicolumn{6}{c}{ No. of elevated modified nucleosides } \\
\hline Measure & 1 & 2 & 3 & 4 & 5 & 6 \\
Specificity & 0.529 & 0.756 & 0.884 & 0.942 & 0.983 & 0.996 \\
Sensitivity & 0.774 & 0.602 & 0.484 & 0.323 & 0.161 & 0.043 \\
Youden index & 0.3 & 0.36 & 0.37 & 0.27 & 0.14 & 0.04 \\
\hline
\end{tabular}

Table V. Sensitivity, specificity and Youden index considering patients with tumor volume $\geq 20 \mathrm{ml}$ for cut-off model using the number of modified nucleosides found at elevated concentration.

\begin{tabular}{lllllll}
\hline & \multicolumn{6}{c}{ No. of elevated modified nucleosides } \\
\hline Measure & 1 & 2 & 3 & 4 & 5 & 6 \\
Specificity & 0.529 & 0.756 & 0.884 & 0.942 & 0.983 & 0.996 \\
Sensitivity & 0.837 & 0.694 & 0.612 & 0.408 & 0.204 & 0.082 \\
Youden index & 0.37 & 0.45 & 0.50 & 0.35 & 0.19 & 0.08 \\
\hline
\end{tabular}

kind of cancer. Table VI shows the significant mNS found in our first study (9) compared with the present study, whereby four $\mathrm{mNS}$ (pseudouridine, cytidine, 2-methylguanosine, N6-methyladenosine) were found to be significant markers in both studies. The previous study included more than $66 \%$ patients with breast, colon and lung cancer, which can be declared as cancer types with a large tumor volume, and not a single case of HNSCC. The mean age of the patients was similar, but in the present study, more male participants were included in the cancer group. This reflects the known imbalance in sex distribution in the case of HNSCC, with more men being affected than women.

Other studies based on bulky tumors, such as lung and breast cancer, also found parts of the mNS pattern (1methyladenosine and $N 2, N 2$-dimethylguanosine) ascertained in our previous study $(20,21)$.

As seen in Figure 1, the pattern of the predominant mNS shifted from pseudouridine in healthy individuals to $\mathrm{N} 6$ methyladenosine among the patients with HNSCC. The emergence of N6-methyladenosine is based on dynamic modification processes which are regulated through highly specific methyltransferases and demethylases. Higher intracellular levels of methyltransferases such as methyltransferase-like 3 (METTL3) might be linked to transformed cells in cancer (22).

Different models were also applied to enhance the hit rate regarding sensitivity and specificity in biomarker studies wherefore we checked them. The cut-off model did not reach a sensitivity and specificity large enough to reliably assess the
Table VI. Comparison between the current study of head and neck squamous cell carcinoma and our previous study with a pool of cancers (significant nucleosides are marked in bold; short names seen in Table).

\begin{tabular}{lcc}
\hline Modified nucleoside* & Our previous study (9) & Current study \\
\hline Psi & + & + \\
C & + & + \\
HXan & - & + \\
U & + & + \\
m3C & + & + \\
m1A & + & + \\
m5C & + & + \\
G & - & + \\
Xan & + & + \\
m1I & + & + \\
L-Tryp & - & + \\
m1G & + & + \\
m2G & + & + \\
m2,2G & + & + \\
m6A & + & + \\
\hline
\end{tabular}

*Please refer to Table I. +: Significantly elevated in patients with cancer; +: not significantly different from controls; -: studied but not detected.

status of a potential patient with the required level of certainty. The neural network also did not achieve this. The main question of whether mNS can be used as markers for cancer leads to the question as to what influence the size of the tumor has. It could be expected that the volume of tumor (the number of cancer cells) is a measure for the production of mNS. This was demonstrated by taking into account patients with a cancer volume of more than $20 \mathrm{ml}$. For these cases, the sensitivity and specificity reach the required magnitude of approximately $95 \%$ for specificity and $>50 \%$ for sensitivity by applying a multilayer perceptron. Figure 3 demonstrates this.

Of note, several confounding factors, such as alcohol and tobacco consumption, which represent the major risk factors for development of HNSCC, might limit the applicability of $\mathrm{mNS}$ as tumor markers.

We demonstrate the possibility of detecting small-volume tumors of HNSCC of about $20 \mathrm{ml}$ total volume with specificity and sensitivity in the conventional range. However, HNSCC of $<20 \mathrm{ml}$ were also reliably detected with acceptable accuracy. The pattern of $\mathrm{mNS}$ in urine of patients with HNSCC differs remarkably from patterns in urine of healthy donors, but also of patients with other cancer entities $(9,10)$, in particular, those known to be rather associated with higher tumor burden [median volume $<50 \mathrm{ml}$ (23)]. However, when HNSCC of smaller volumes are present, confounders such as the classical risk factors for HNSCC development, namely tobacco and alcohol consumption may cause reduced accuracy of cancer detection based on urinary mNS, even if advanced statistical methods are used for data interpretation. 


\section{Conclusion}

Post-transcriptional modification of RNA by numerous processes such as methylation produces mNS known for being involved in shaping the structure of tRNA and in fine-tuning of gene expression by modification of mRNA. As mNS cannot be recycled and are excreted, urinary mNS reflect the RNA turnover of the whole body. By comparison of $\mathrm{mNS}$ in urine of patients with HNSCC with that of healthy controls, we demonstrated essentially different mNS patterns which allow for accurate discrimination between healthy persons and patients with tumors $\geq 20 \mathrm{mI}$, making them excellent tumor markers allowing for non-invasive detection of cancer.

\section{Conflicts of Interest}

The Authors declare that they have no conflict of interest concerning this publication.

\section{References}

1 Wang S, Zhao X, Mao Y and Cheng Y: Novel approach for developing urinary nucleosides profile by capillary electrophoresismass spectrometry. J Chromatog A 1147: 254-260, 2007.

2 Bullinger D, Fröhlich H, Klaus F, Neubauer H, Frickenschmidt A, Henneges C, Zell A, Laufer S, Gleiter $\mathrm{CH}$, Liebich $\mathrm{H}$ and Kammerer B: Bioinformatical evaluation of modified nucleosides as biomedical markers in diagnosis of breast cancer. Anal Chim Acta 618: 29-34, 2008.

3 Hsu W, Lin W, Tsai Y, Lin C, Wang H, Jeng L, Lee C, Lin Y, Lai $\mathrm{C}$ and Tsai F: Analysis of urinary nucleosides as potential tumor markers in human breast cancer by high performance liquid chromatography/electrospray ionization tandem mass spectrometry. Clin Chim Acta 412: 1861-1866, 2011.

4 Willmann L, Erbes T, Krieger S, Trafkowski J, Rodamer M and Kammerer B: Metabolome analysis via comprehensive twodimensional liquid chromatography: identification of modified nucleosides from RNA metabolism. Anal Bioanal Chem 407: 3555-3566, 2015.

5 Cantara WA, Crain PF, Rozenski J, McCloskey JA, Harris KA, Zhang X, Vendeix FAP, Fabris D and Agris PF: The RNA Modification Database, RNAMDB: 2011 update. Nucleic Acids Res 39: D195-201, 2011.

6 Boschi-Muller S and Motorin Y: Chemistry enters nucleic acids biology: enzymatic mechanisms of RNA modification. Biochemistry 78: 1392-1404, 2013.

7 Zheng Y, Xu G, Liu D, Xiong J, Zhang P, Zhang C, Yang Q and Lv S: Study of urinary nucleosides as biological marker in cancer patients analyzed by micellar electrokinetic capillary chromatography. Electrophoresis 23: 4104-4109, 2002.

8 Borek E, Baliga BS, Gehrke CW, Kuo CW, Belman S, Troll W and Waalkes TP: High turnover rate of transfer RNA in tumor tissue. Cancer Res 37: 3362-3366, 1977.

9 Seidel A, Brunner S, Seidel P, Fritz GI and Herbarth O: Modified nucleosides: an accurate tumour marker for clinical diagnosis of cancer, early detection and therapy control. $\mathrm{Br} \mathbf{J}$ Cancer 94: 1726-1733, 2006.

10 Seidel P, Seidel A and Herbarth O: Multilayer perceptron tumour diagnosis based on chromatography analysis of urinary nucleosides. Neural Netw 20: 646-651, 2007.
11 Seidel A, Seidel P, Manuwald O and Herbarth O: Modified nucleosides as biomarkers for early cancer diagnose in exposed populations. Environ Toxicol 30(8): 956-967, 2015.

12 Gehrke CW and Kuo KC: Ribonucleoside analysis by reversedphase high-performance liquid chromatography. J Chromatog 471: 3-36, 1989.

13 Sobin LH, Gospodarowicz MK and Wittekind C: TNM Classification of Malignant Tumours. Chichester, West Sussex, UK, Hoboken, NJ, Wiley-Blackwell, 2009.

14 Mueller S, Wichmann G, Dornheim L, Roessling I, Bertolini J, Preim B, Dietz A and Boehm A: Different approaches to volume assessment of lymph nodes in computer tomography scans of head and neck squamous cell carcinoma in comparison with a real gold standard. ANZ J Surg 82: 737-741, 2012.

15 Sander G, Topp H, Wieland J, Heller-Schöch G and Schöch G: Possible use of urinary modified RNA metabolites in the measurement of RNA turnover in the human body. Human nutrition. Clin Nutr 40: 103-118, 1986.

16 Schöch G, Topp H, Held A, Heller-Schöch G, Ballauff A, Manz $\mathrm{F}$ and Sander G: Interrelation between whole-body turnover rates of RNA and protein. Eur J Clin Nutr 44: 647-658, 1990.

17 Roszkowski K, Gackowski D, Rozalski R, Dziaman T, Siomek A, Guz J, Szpila A, Foksinski M and Olinski R: Small field radiotherapy of head and neck cancer patients is responsible for oxidatively damaged DNA/oxidative stress on the level of a whole organism. Int J Cancer 123: 1964-1967, 2008.

18 Dudley E, Lemiere F, van Dongen W, Langridge JI, El-Sharkawi S, Games DE, Esmans EL and Newton RP: Analysis of urinary nucleosides. III. Identification of 5'-deoxycytidine in urine of a patient with head and neck cancer. Rapid Commun Mass Spect 17: 1132-1136, 2003.

19 Bullinger D, Fux R, Nicholson G, Plontke S, Belka C, Laufer S, Gleiter $\mathrm{CH}$ and Kammerer B: Identification of urinary modified nucleosides and ribosylated metabolites in humans via combined ESI-FTICR MS and ESI-IT MS analysis. J Am Soc Mass Spect 19: 1500-1513, 2008.

20 McEntire JE, Kuo KC, Smith ME, Stalling DL, Richens JW, Zumwalt RW, Gehrke CW and Papermaster BW: Classification of lung cancer patients and controls by chromatography of modified nucleosides in serum. Cancer Res 49: 1057-1062, 1989.

21 Cho S, Jung BH, Lee SH, Lee W, Kong G and Chung BC: Direct determination of nucleosides in the urine of patients with breast cancer using column-switching liquid chromatography-tandem mass spectrometry. Biomed Chromatog 20: 1229-1236, 2006.

22 Niu Y, Zhao X, Wu Y, Li M, Wang X and Yang Y: N6-methyladenosine (m6A) in RNA: an old modification with a novel epigenetic function. Genomics, Proteomics Bioinf 11: 8-17, 2013.

23 Arredondo J, Gonzalez I, Baixauli J, Martinez P, Rodriguez J, Pastor C, Ribelles MJ, Sola JJ and Hernandez-Lizoain JL: Tumor response assessment in locally advanced colon cancer after neoadjuvant chemotherapy. J Gastrointest Oncol 5: 104-111, 2014.

24 Tang L, Chen Y, Mao Y, Wang Z, Guo R, Chen L, Tian L, Lin A, Li L, Sun Y and Ma J: Validation of the 8th Edition of the UICC/AJCC Staging System for Nasopharyngeal Carcinoma From Endemic Areas in the Intensity-Modulated Radiotherapy Era. J NatI Comp Cancer Netw 15: 913-919, 2017.

Received September 19, 2018

Revised October 8, 2018

Accepted October 12, 2018 